\title{
SCHÜTZ, SEEBOHM E A CIÊNCIA DA CULTURA
}

Lester Embree

Florida Atlantic University

SÍNTESE: Alfred Schütz enfatiza os métodos de interpretação das ciências sociais. Thomas Seebohm salienta a interpretação dos textos e dos vestígios, que são essenciais para as ciências históricas. Neste contexto, os seus esforços são, na maior parte, mutuamente complementares, e em conjunto fazem avançar a teoria constitutiva fenomenológica das ciências genéricas da cultura.

\section{Introdução}

Este esboço, sobretudo comparativo, está relacionado com a teoria geral das ciências da cultura, que compreendem não somente as ciências sociais, mas também as eiêneias histórieas, incturintor a Arqueologia. Alfred Schütz deu uma grande contribuição para a primeira questão, mas preocupou-se menos com as ciências históricas, ' enquanto que o novo livro de Thomas Seebohm contribui bastante no que diz respeito ao método histórico-filológico. Ambos acham a Fenomenologia Constitutiva da Atitude Natural, de Husserl, suficiente para os seus propósitos filosóficos. ${ }^{2}$ Além do mais, as suas contribuições confirmam-se ou complementam-se substancialmente uma à outra. Por conseguinte, as principais semelhanças

Lester Embree, "A Problem in Schutz's Theory of the Historical Sciences with an Illustration from the Women's Liberation Movement," Human Studies 27:281 - 306, 2004.

2 Thomas M. Seebohm, Hermeneutics: Method and Methodology (Dordrecht: Kluwer Academic Publishers, 2004), 2, 98 (a partir deste ponto é citado no texto como "HMM"); Alfred Schutz, Collected Papers, Vol. I, ed. Maurice Natanson (The Hague: Martinus Nijhoff, 1962), 132 (citado no texto como "CP I"). A fonte de Sclututz de Husserl é do "Epilogo" para a traduçăo de Boyce Gibson das Ideen I, re-tranduzida em Edmund Husserl, Ideas Pertaining to a Pure Phenomenology and to a Phenomenological Philosophy, Second Book, trad. Richard Rojcewicz e André Schuwer (Dordrecht: Kluwer Academic Publishers, 1989), $405 \mathrm{ff}$. 
e diferenças nos seus resultados serão revistas neste artigo, primeiramente no que diz respeito à noção de "compreensão" e, de seguida, no que se refere às questões do método, da metodologia e da teoria da ciência. Por último, faremos algumas observações acerca do seu método compartilhado.

\section{Contributos para uma teoria fenomenológica da compreensão}

A Hermeneutics, de Thomas Seebohm, está dividida três partes. A primeira apresenta uma história da interpretação dos textos e dos vestígios, que parece mais plausível do que aquela que encontramos na Wahrheit und Methode, de Hans-Georg Gadamer (1962). A terceira parte da obra é dedicada aos cânones do método histórico-filológico, que serão comparados, muito sucintamente, com os principais pressupostos metodológicos de Schütz na parte final deste ensaio. O que nos deve ocupar na primeira parte desta comparação é a segunda parte da obra de Seebohm, que se intitula "Para uma Teoria Geral da Compreensão". Nesta parte, Seebohm ultrapassa Schütz na sua referência ao passado, assim como Schütz ultrapassa Seebohm nas suas referências ao terreno contemporâneo.

Alfred Schütz poderia ter aceitado com facilidade a definição de Seebohm, mediante a qual “o termo 'compreensão' parece ser coextensivo com o reino de actividades cognitivas no seu todo - em termos fenomenológicos, com todas as espécies de actos intencionais e sínteses activas" (HMM 93). Schütz afirma que é necessário "distinguir claramente entre Verstehen (1) enquanto modo de experiência do conhecimento do senso-comum das coisas humanas, (2) enquanto problema epistemológico e (3) enquanto método específico das ciências sociais" (CP I, 57). Do mesmo modo, ele acrescenta:

O conhecimento do senso-comum na vida diária é suficiente para lidar com homens nossos semelhantes, com os objectos culturais, com as instituições sociais, em suma, com a realidade social. Isto deve-se ao facto de o mundo (natural e social) ser, desde o princípio, um mundo intersubjectivo e [...] porque o conhecimento que temos dele é socializado de diversas formas. Além disso, o mundo social é experimentado, desde o início, como um mundo significante. $\mathrm{O}$ corpo do Outro não é experienciado como um organismo, mas como um ser humano nosso semelhante. O seu comportamento exterior não é entendido como um fenómeno no espaço-tempo do mundo externo, mas como a acção de um semelhante. Normalmente, nós "sabemos" o que o outro faz, a razão por que o faz, porque faz isso neste momento particular e nestas circunstâncias particulares. Isto significa que nós experienciamos as acções do nosso semelhante em conformidade com as suas motivações e objectivos. Do mesmo modo, nós experienciamos os objectos culturais em termos da acção humana de que eles são o resultado. (CP I, 55f.) 
Seebohm concorda em grande parte, se bem que utilize o termo "artefacto" para aquilo que Schütz denomina "objecto cultural" e defina o "outro" de um modo mais abrangente, como " um ser humano ou um animal que possui um corpo vivo e uma experiência interna das suas próprias sensações, sentimentos e impulsos" (HMM 95). Contrariamente, Schütz faz referência, mas não se pronuncia sobre os animais não-humanos. No entanto, ambos estão preocupados com a questão do sentido. ${ }^{3}$ Como o "sentido" está muitas vezes relacionado com a linguagem, é importante referir que Seebohm distingue entre compreensão linguística e pré-linguística e, por conseguinte, entre sentido linguístico e pré-linguístico (HMM 97), uma distinção que também é feita pontualmente por Schütz. ${ }^{4}$

Ambos os autores começam a sua reflexão com o eu e os outros que estão dentro do campo de alcance directo, experiencial e prático, uns dos outros, coisa que significa dizer que ambos começam a partir dessa zona do mundo-da-vida que pode ser designada como "situação consocial." é crucial para ambos é que, enquanto as tentativas da ciência para a compreensão têm de seguir métodos, a compreensão pré-científica deve ser o ponto de partida, de maneira a esclarecer não só o que é compreendido na ciência, mas também onde se baseiam esses mesmos métodos científicos.

Porém, Seebohm não apenas reconhece a compreensão pré-científica e científica, mas também reconhece três espécies diferentes e mais alargadas de compreensão: compreensão animal, compreensão elementar e compreensão superior.

3 Se o mundo social é definido segundo as relações com os Outros, não é impertinente que Schutz reconheça experiências que, para um Eu, "não são subjectivamentẹ significativas", por exemplo, "os reflexos meramente fisiológicos, como o reflexo do joelho a esticar, a contracção da pupila, pestanejar, corar... a minha postura, a minha expressão facial, o meu temperamento, aquelas manifestações da minha vida espontânea que determinam certas características da minha caligrafia, podem ser objecto de uma interpretação grafológica, etc.," que são designadas por Schutz como "experiências essencialmente actuais" (CP I 210f). Essas experiências que não são subjectivamente significativas, apesar disso, são interpretadas pelos outros.

4 "Uma obra de música é um contexto significativo. É significativo para o compositor; e pode ser compreendido como significativo para o ouvinte; e cabe ao intérprete a tarefa de revelar o verdadeiro significado. Aplicados ao domínio musical, os termos 'significado' e 'contexto', 'compreensão' e 'interpretação' são usados, todavia, de um modo muito específico que difere dos outros sistemas de significado como no caso das línguas. [...] A música é uma instância com um contexto significativo sem referência a um esquema conceptual e, mais especificamente, sem uma referência imediata aos objectos do mundo onde habitamos, sem referência a propriedades ou funções desses objectos. A música não tem uma função representativa. (A notação musical tem certamente uma função representativa.)." Alfred Schutz, Collected Papers, Vol. IV, ed. Helmut Wagner e George Psathas em colaboração com Fred Kersten (Dordrecht: Kluwer Academic Publishers, 1996), 243f. (a partir deste ponto é citado no texto como "CP IV"). Cf. Alfred Schutz, Collected Papers, Vol. II, ed. Arvid Brodersen (The Hague: Martinus Nijhoff, 1964), pp. 159 - 178 (citado no texto como "CP II”).

5 Lester Embree, "Phenomenology of the Consocial Situation: Advancing the Problems," in Space, Time, and Culture, ed. David Carr and CHEUNG, Chan-Fai (Dordrecht: Kluwer Academic Publishers, 2004), pp. $119-133$. 
A. No domínio da compreensão animal, os não-humanos não apenas se compreendem uns aos outros, como também podem compreender os humanos, assim como os humanos podem compreendê-los. Contudo, existem limites neste tipo de compreensão.

O tempo partilhado nos encontros entre animais e na compreensão animal cinge-se exclusivamente ao presente actual. Não se pode compará-lo com o tempo partilhado no mundo-da-vida humano, com um passado, uma tradição e expectativas de um futuro que se partilham, pondo de parte o tempo objectivo do mundo-da-vida. Neste tempo/espaço comuns do presente actual, temos, contudo, objectos partilhados, que cada um sente de perspectivas diferentes, perspectivas que variam de acordo com cinesteses mutuamente observáveis. Os animais estão a este nível de objectos de primeira ordem, intersubjectivamente dados. Não apenas um pau, no tempo partilhado entre cão e seu dono, quando brincam no jardim, mas um osso, pelo qual dois cães lutam, é já um tal objecto real partilhado. (HMM 103)

Este último ponto pode ser aprofundado aplicando a noção de "área de manipulação", que Schütz recebeu de George Herbert Mead, às descrições da compreensão e interacções animais de Seebohm (cf. CP I 223). No entanto, mais uma vez, Schütz quase não menciona os não-humanos (cf. CP II 234).

Seebohm escreve acerca das "expressões corporais da vida", enquanto mensagens que não são dirigidas para outros em particular, como uma cadela com cio, em comparação com outras mensagens - como rugir e rosnar - que são realmente dirigidas para determinados outros, dentro do tempo/espaço partilhado da situação consocial. No entanto, o autor considera que, a este respeito, é preferível referirmo-nos a uma "comunicação corporal não-verbal", em vez de uma "linguagem do corpo", porque, apesar de as expressões corporais serem sinais, não são simbólicas e não são específicas de uma cultura, como no caso das línguas. Ele é céptico no que toca aos não-humanos comunicarem mediante expressões propriamente simbólicas e não meramente indexicais, se bem que reconheça que os signos indexicais ocorrem efectivamente, tanto na comunicação humana como na não-humana (HMM 104). Schütz também reserva uma alínea a esta comunicação não-verbal, mas é algo que desempenha um papel menos proeminente nas suas análises. ${ }^{6}$

Por último, os tipos de compreensão mais elevados estão unilateralmente fundados na compreensão animal e, quando os tipos mais elevados falham, apenas resta "a compreensão das expressões corporais da vida dos outros seres vivos, como a raiva, a agressividade, o medo, o prazer, a dor, a disposição para cooperar pacificamente, e outras coisas semelhantes"

6 Cf. Lester Embree, "A Problem in Alfred Schutz's Methodology of the Cultural Sciences," trans. IRIE, Masakatsu, Bunku to Shakai 1 (1999), pp. 105 - 131. 
(HMM 93). Também é necessário reconhecer que existe a aprendizagem, a brincadeira e mesmo o engano ao nível da compreensão animal, ocorrendo esta última nos animais humanos quando, por exemplo, um sorriso precede imediatamente um ataque (HMM 114f).

B. Seebohm está de acordo com a distinção entre compreensão superior e compreensão elementar, de Wilhelm Dilthey: "A compreensão elementar pode ser caracterizada, em geral, como um modo de compreensão irreflectida no interior de contextos culturais. É aquele tipo de compreensão que se exige para as interacções diárias no interior de um mundo-da-vida cultural. A compreensão superior pode caracterizar-se, em geral, como compreensão do contexto cultural como um todo, ou como compreensão de certos aspectos da sua estrutura, representando pequenos todos em si mesmos (HMM 106).

No domínio da compreensão elementar, são encontrados sistemas de artefactos, nos quais estão indiciados os artesãos, assim como os utensílios, matérias-primas e produtos (HMM 112). Verifica-se uma cooperação, indicando a incapacidade para cooperar um colapso na compreensão. A cooperação é dirigida para objectivos, frequentemente, segundo modos coordenados, por exemplo, o comprar e o vender. Os impulsos, tal como o impulso sexual, também se apresentam neste nível, e estão submetidos a regras sociais rudimentares. A cooperação requer a linguagem em sentido próprio, se bem que restringida às necessidades das actividades do dia-a-dia. Qualquer expressão de vida imediata pode converter-se em "matéria de signo" no discurso e/ou ter uma função auxiliar. Realmente, "é um facto que a voz e os gestos visíveis são as expressões de vida mais efectivas utilizadas pelos homens, assim como pelos animais superiores" (HMM 109). A voz e os gestos não são expressões fixas de vida, ao passo que os artefactos, inclusive o discurso escrito, o são.

Schütz poderia perfeitamente ter aceitado esta análise no que respeita ao que se entende por elementar. No entanto, já a este nível ultrapassa Seebohm em diversos aspectos. Em primeiro lugar, o autor distingue os "contemporâneos", dos "predecessores" e "sucessores". Para Schütz, os contemporâneos são os outros que vivem ao mesmo tempo que um eu, mas que não partilham com ele o mesmo espaço. No entanto, pode haver uma compreensão indirecta dos contemporâneos, bem como uma acção indirecta sobre eles, e tal compreensão e acção podem ser recíprocos. Por outras palavras, as relações com os contemporâneos transcendem a "situação consocial", ou seja, o presente vivido partilhado, no qual ocorre toda a compreensão animal.

Portanto, para Schütz, o tipo de pensamento que está envolvido no que Seebohm designa de compreensão elementar é, basicamente, o senso-comum, comunicado na linguagem comum, e gira em torno da idealização 
pré-científica das perspectivas; a origem social e a distribuição do conhecimento do senso-comum; a tipificação da rotina através dos meios de construção do senso-comum, que incluem, por exemplo, os tipos de cursos-de-acção, bem como os tipos de ideias (CP I 10.27). Seebohm não discute a tipificação, que é caracterizada por Schütz como "aquela forma de abstracção que conduz àquilo que é mais ou menos estandardizado e vago, à conceptualização do pensamento do senso-comum e à necessária ambiguidade dos termos do vernáculo". (CP I 323) As análises de Schütz poderiam ser acrescentadas à compreensão elementar de Seebohm.

Além disso, Schütz analisa reflexivamente o modo como as acções dos indivíduos se tornam originalmente significativas para si próprios no processo de planear. Mais ainda, além destes "sentidos subjectivos", existem "sentidos objectivos" não só para os parceiros que praticam a acção, mas também para os observadores das acções e interacções da vida diária, bem como para observadores na Ciência e na Filosofia (CP II 275). Schütz dedica mais atenção à teleologia da acção do que Seebohm.

C. Se a compreensão elementar "é uma compreensão de como fazer coisas", a compreensão superior, "pode ser caracterizada como uma compreensão do que as coisas são" (HMM 117). Por outras palavras, as estruturas da vida diária são o resultado da tradição, e as pessoas seguem padrões pré-determinados de como as coisas são feitas (Schütz falou de "receitas") sem compreender estes padrões mais vastos, que é precisamente aquilo que procura fazer a compreensão superior. É contemplativa; e surge muitas vezes mediante subversões culturais (que incluem o contacto com outras culturas); tematiza estruturas que transcendem as necessidades imediatas; e usa uma linguagem que as ultrapassa. Schütz reconhece, certamente, o "padrão cultural da vida em grupo" (cf. CP II 92), e elabora uma série de observações a esse respeito, incluindo a noção de vida social como algo histórico (CP II 230f.). Contudo, ele não reconhece, de um modo distinto, os dois tipos de compreensão superior, que são descritos por Seebohm - nomeadamente, a interpretação ou compreensão superiores de primeira ordem e a interpretação ou compreensão superiores de segunda ordem.

A compreensão superior de primeira ordem está relacionada com as instituições sociais, como a família, a cidade, a tribo, o comando e o Estado, assim como com as instituições religiosas e os mitos criados pelos poetas e profetas (o acto de legislar faz parte da elaboração mitológica). Além do mais, a compreensão também se desenvolve na Filosofia, na Ciência, no Direito e na Literatura, quando estas se separam da Religião. A compreensão superior está associada às "expressões de vida fixas, tais como as esculturas, as pinturas, os ornamentos, os templos, ou formas de expressão de vida não-fixas, como os rituais, a dança e, sobretudo, o discurso oral" (HMM 117). A natureza que se encontra para além do território 
domesticado (bem como o nosso próprio corpo) é experimentada, primeiramente, como algo simplesmente surpreendente, mas o eu e os outros são compreendidos segundo funções sociais específicas, por exemplo, no papel de "esposa ou marido, chefe ou feiticeiro, fazendeiro ou caçador, guerreiro ou padre" (HMM 119). Por conseguinte, todo o mundo-da-vida pode ser considerado na compreensão superior de primeira ordem, e pode-se criar ou rever uma visão do mundo.

De acordo com Schütz, as Ciências Sociais podem estar relacionadas com a compreensão superior. Os seus temas fazem parte da região dos contemporâneos. Economia, Ciência Política, Sociologia, etc., são desenvolvidas em atitude teorética, e os seus modelos são elaborados a partir de construções científicas, ou são interpretações das construções do senso-comum ou das interpretações da vida diária. Por outras palavras, o segundo nível de interpretação, de Schütz, começa no primeiro dos dois níveis que Seebohm designa de "compreensão superior", enquanto que as interpretações do "senso-comum", descritas por Schütz, correspondem ao nível do "compreensão elementar", na tese de Seebohm.

A compreensão superior de segunda ordem envolve aquilo que Dilthey designa de "reviver", e centra-se na geração das tradições culturais. Profetas, padres, rapsodos, xamãs e feiticeiros realizam interpretações de segunda ordem dos mitos oferecidos pela interpretação de primeira ordem. Os "génios" têm um grande impacto e podem manifestar-se na Arte, no Direito, na Filosofia, na Ciência e na Tecnologia. Neste tipo de compreensão superior, reconhece-se acima de tudo que a tradição histórica determina o modo como as coisas devem ser feitas. Schütz estava ciente de que as estruturas da vida diária são tradicionais, mas, mais uma vez, não se debruçou muito sobre esta questão nas suas obras.

As tradições culturais, para Seebohm, podem incluir textos, e, por conseguinte, serem literárias, no sentido mais abrangente do termo, ou também podem ser não-literárias. No último caso, os discursos podem ir além da situação consocial dos contemporâneos, predecessores e sucessores, porém, a compreensão indirecta destes discursos é baseada em expressões de vida não-fixas na situação consocial. O reviver do passado, na compreensão elementar, depende da memória, durante os rituais, e é orientado, normalmente, por artefactos e pelas relações entre mestre e aprendiz. Mesmo para os reprodutores profissionais da compreensão superior de segunda ordem, é difícil reproduzir a interpretação de primeira ordem do profeta, quando lhe falta uma tal orientação.

Podem ocorrer grandes alterações nos mitos apenas transmitidos oralmente. Essas alterações só são.reconhecidas numa análise exterior, através de uma investigação cultural e científica, incluindo a Arqueologia. As alterações devem-se ao descuido; questões estilísticas; novos artefactos como as armas; contactos culturais que trazem conhecimentos para se produzir 
novos produtos; a necessidade de integrar estruturas sociais alteradas, especialmente, os relacionamentos de poder. As tradições não-literárias podem recuperar a sua autoridade depois dessas mudanças, embora também possam morrer devido a elas.

Nas culturas literárias, não se verifica tanto a necessidade de memorizar. Graças às expressões de vida fixas, os discursos podem ser reproduzidos fora do contexto original da situação consocial. Os textos, enquanto tal, podem ser enviados tanto para os sucessores como para os contemporâneos, e podem ser recebidos dos predecessores, como Schütz muito bem sabia. As leis escritas podem influenciar o comportamento futuro e sobreviver às mudanças de chefia. E aí pode estar o poder central por sobre vastos impérios.

Segundo Seebohm, a escrita possui três "meta-géneros": (1) existe uma literatura com finalidades práticas, tal é o caso do Direito, da Historiografia e da Ciência nos seus primórdios, e da literatura técnica; (2) existe uma literatura de compreensão mais elevada dos épicos e o teatro de culto, que explica os deuses e a condição humana, que pode igualmente abarcar a literatura teológica e filosófica (e até a literatura poética para entretenimento); e (3) existe a literatura dos eruditos, cujos precursores foram os gramáticos e filólogos Helenistas, que inclui comentários, interpretações e crítica literária.

A erudição é um termo neutro que pode ser aplicado às mais elevadas tradições literárias. Um erudito é alguém que conhece os livros que pertencem à sua tradição literária. $\mathrm{O}$ erudito elabora comentários sobre as obras tradicionais. [...] O resultado é, independentemente de se usar ou não esta palavra, a Hermenêutica, isto é, um conjunto de regras e princípios que orientam a arte dos eruditos. [...]

Isto leva ao desenvolvimento de uma metodologia da Hermenêutica, ou seja, não leva apenas a uma colecção de regras, mas a um sistema rigoroso de procedimentos metódicos, aliado à comprovação ou, no mínimo, ao apuramento das razões que certificam a validade objectiva das interpretações orientadas pelos métodos (HMM 149, 152).

\section{Método e metodologia}

A terceira parte da Hermeneutics, de Seebohm, é dedicada às questões metódicas e metodológicas. É provável que as suas cem páginas retomem a discussão dos cânones da Hermenêutica. Contrariamente, Schütz não descreve o desenvolvimento histórico da sua teoria da ciência, embora inclua regras de procedimento, que costuma designar de "postulados". A sua "metodologia", num sentido abrangente, coaduna-se melhor com a sua 
expressão alternativa, Wissenschaftslehre (teoria da ciência), porque também inclui mais dois componentes, de entre os quais, o primeiro ocupa-se da classificação das ciências.

Neste contexto, Schütz e Seebohm coincidem fundamentalmente. Seebohm concorda com a distinção de Dilthey entre as ciências humanas históricas e "sistemáticas". As ciências sistemáticas - tal como as "ciências sociais", de Schütz - incluem a Economia, a Jurisprudência, a Psicologia e a Sociologia, enquanto as ciências históricas incluem a Arqueologia, a História e a Filologia, tanto para Schütz como para Seebohm (HMM, 1, 82, 246).

$\mathrm{O}$ segundo componente da teoria da ciência de Schütz dedica-se à clarificação de conceitos básicos. Seebohm também reconhece a importância desta questão, todavia, a sua extensa clarificação de conceitos não será aqui tratada.

O mais importante é a asserção, de Seebohm, segundo a qual, para a ciência em geral, "a meta é um conhecimento que apresente - pelo menos para todos os investigadores que seguem o mesmo método - o carácter de uma objectividade reconhecida intersubjectivamente, ou seja, que pode ser alcançada de igual modo em procedimentos semelhantes" (HMM 153). Além disso, Seebohm considera a prioridade fenomenológica das Ciências Humanas - ou melhor, da cultura - sobre as Ciências Naturais, na medida em que o mundo-da-vida cultural é concreto e a natureza é uma abstracção feita a partir dele:

Têm existido dois pontos de vista implícitos, que governam o debate metodológico das chamadas Ciências Humanas e da História. O que mais se divulgou foi a tese positivista, segundo a qual existe apenas um único método científico, e este é o método das Ciências Naturais. As Ciências Humanas só são entendidas como ciências até o ponto em que tais métodos lhes são aplicados. O resto é poesia. O outro ponto de vista procurou reclamar, desde Dilthey, que as Ciências Humanas têm os seus próprios princípios metodológicos. Não as leis causais, mas a compreensão, é o essencial para as Ciências Humanas. Encarada de um ponto de vista fenomenológico, a diferença tem ainda mais razões substanciais. As Ciências Naturais requerem reduções abstractivas. $\mathrm{O}$ que é colocado entre parênteses nessas reduções é o mundo-da-vida e, com ele, o interesse por contextos culturais diferentes. Ora os objectos das Ciências Humanas são, precisamente, o mundo-da-vida e os seus diferentes contextos culturais, no passado e no presente. (HMM 153, cf. CP I 58)

As Ciências Humanas diferem das primeiras disciplinas de "estudos humanísticos" na necessidade de mostrar uma garantia para a objectividade, que é irredutível àquilo que garante a objectividade nas Ciências Naturais.

E, com isto, para Seebohm, a acentuação salta do "método" para a "metodologia". Até agora, as tentativas para uma metodologia da Arqueolo- 
gia não foram bem sucedidas, sendo os artefactos diferentes dos textos (HMM 153), e mesmo com as contribuições de Johann Gustav Droysen e Dilthey, as coisas não estão melhores para a História (HMM 246). A metodologia hermenêutica, em geral, é, realmente, a de uma interpretação e crítica dos textos e vestígios de todas as espécies. No entanto, dado que a hermenêutica arqueológica e a histórica estão subdesenvolvidas, Seebohm centra-se na interpretação e crítica dos textos, que tiveram um grande avanço no século XIX. A chamada "Filologia", bem como a "erudição", são um tipo de investigação que produz textos sobre textos. Por conseguinte, "o problema principal diz respeito aos princípios metodológicos que podem servir como garantia para algum tipo de objectividade nas ciências humanas histórico-filológicas" (HMM 153). Seebohm trata principalmente de niveis, de todos e partes e de falsificação (mais uma vez, existem uma série de detalhes que são ignorados neste esboço comparativo).

Existem três níveis que pertencem à compreensão dos textos: leitura pré-metódica, leitura metódica e leitura metodologicamente orientada. A leitura pré-metódica é mecânica, enquanto que a compreensão erudita, que envolve regras, foi desde cedo considerada como uma arte, coisa que a converte numa disciplina como o Direito, em vez de numa ciência. O "método da Hermenêutica" apresenta uma série de regras de erudição ordenadas sistematicamente. Isso varia consoante a cultura, contudo, no século XIX, reconheceu-se já que alguns dos componentes são universais. Assim, as regras metodológicas vão para além disto e requerem uma justificação pela crítica.

A discussão filológica, no século XIX, distinguiu, em conformidade, dois níveis na hermenêutica inferior e mais dois níveis na hermenêutica superior. O primeiro nível da hermenêutica inferior envolve regras de gramática e dicionários, para compreender as palavras e as frases, e qualquer interpretação que viole as regras de gramática ou que deturpe as palavras pode ser rejeitada na fase da crítica. O segundo nível da hermenêutica inferior explica factos e termos técnicos nas frases e passagens, e, normalmente, ocorre nos comentários linha-a-linha. Baseia-se em outras passagens do mesmo texto, em outros textos do mesmo autor, ou em outros textos do mesmo género; a crítica, a este nível inferior de hermenêutica, baseia-se em contradizer factos e testemunhos.

Os dois níveis de hermenêutica superior são a interpretação e a crítica do estilo e/ou da individualidade do autor, e a interpretação e a crítica do género. As interpretações de nível superior são rejeitadas se forem incompatíveis com as interpretações de nível inferior. Houve uma grande disputa para determinar se os níveis são ou não são disciplinas independentes, bem como de que maneira podem ser distinguidos. Todavia, o que está aqui em causa é que aquilo que estabelece a distinção entre o "metódico" e o "metodológico", é uma hierarquia de níveis onde as interpretações num nível supe- 
rior não podem contar como garantia se entrarem em conflito com o que está garantido nos níveis inferiores.

Alfred Schütz parece não ter estudado os debates metodológicos sobre a Hermenêutica no século XIX, ${ }^{7}$ nem sequer menciona uma fase semelhante, meramente metódica, daquilo que se poderia chamar "Estudos Sociais", que antecedem a emergência das Ciências Sociais. No entanto, o autor está interessado em que as Ciências Sociais atinjam o "estado teorético". 8 No entanto, o mais importante é que ele reconhece uma hierarquia de níveis na teoria da ciência, na qual o mais elevado depende do inferior (Ver a Figura 1). Acima daquilo que se pode chamar de investigação directa, existe uma teoria da própria disciplina, a que se dedicam os membros de uma determinada ciência, por exemplo, Max Weber para a Sociologia. E, acima disso, existe aquilo que poderemos chamar de teoria geral da ciência, a que se dedicam filósofos como Schütz, que se ocupa das espécies e dos géneros da ciência, por exemplo, ciência social e ciência da cultura.

Metodologia filosófica ou teoria geral da ciência

diz respeito a tudo o que se segue

Metodologia ou teoria da ciência elaborada por cientistas

diz respeito a tudo o que se segue

Investigação directa social científica

diz respeito a

Interpretação do senso-comum

Figura 1

7 O seu único comentário a este respeito: "Em Filologia é sempre uma questão básica saber se aquilo que está a ser estudado é o sentido objectivo de uma palavra num tempo definido no interior duma área definida da linguagem ou, segundo, o sentido objectivo que uma palavra adquire no seu uso num autor particular ou num determinado circulo de críticos ou, terceiro, o sentido ocasional que lhe é atribuído no contexto do discurso.", Alfred Schutz, Der sinnhafte Aufbau der sozialen Welt, Vienna, Springer, 1932, §28, citação de Alfred Schutz, The Phenomenology of the Social World, trad. George Walsh and Frederick Lehnert, Evansto, IL, Northwestern University Press, 1967, p. 138, cf. CP I 333; Citado no texto como "PSW." A palavra "hermenêutica" também surge no texto relacionada com uma defesa não muito desenvolvida de Dilthey contra os mal-entendidos que associam a "Hermenêutica" com uma espécie de visão mística [Schau]" (CP IV 92).

8 "Em cada ramo das Ciências Sociais que chegaram a um estado teorético do seu desenvolvimento existe uma hipótese fundamental onde ambos definem os campos de investigação e fornecem os princípios para a construção do sistema de tipos ideais. Uma hipótese tão fundamental, por exemplo, é na Economia Clássica o princípio utilitário, e na Economia Moderna é o princípio marginal." (CP II 87); cf. Alfred Schutz, The Theory of Social Action, ed. Richard Grathoff, Bloomington, Indiana University Press, 1978, 211. 
Seebohm aproxima-se da questão do todo e partes através do segundo cânone de Friedrich Ernst Daniel Schleiermacher, cujos cânones são os "dois princípios básicos e inseparáveis da Hermenêutica" (HMM 164). O segundo cânone tem dois problemas: o de como reconhecer o "escopo", a intenção, ou finalidade do texto, e o da circularidade. Pode compreender-se facilmente o lugar histórico de um texto num contexto de outros textos, se um sistema de géneros for estabelecido; porém, se for um texto eminente ou se pertencer a um novo género, existem dificuldades. Por vezes, a finalidade de um texto é explícita ou é imediatamente implícita, como acontece mesmo em textos eminentes de Direito (o Direito existindo para o bem-comum), mas outros géneros são mais difíceis, especialmente se estão envolvidos artefactos, por exemplo, a Pintura.

Um círculo parece subentendido quando o segundo cânone é formulado como se segue:

A compreensão do todo implica a compreensão das partes, e vice-versa.

Trata-se da questão de uma palavra ou palavras serem compreendidas com base no contexto. Mas o contexto está próximo das palavras, de todo o texto, de toda obra, ou de todo do género? Quando Dilthey aplicou o segundo cânone de Schleiermacher a todos níveis na hermenêutica metodológica, foram postos a descoberto sérios equívocos nos termos "todo", "parte" e "circulo", que diferem da gramática, história, género, etc. O problema dos círculos, discutido longamente por Seebohm, será estudado noutro ensaio.

Além disso, o primeiro cânone foi considerado, pela Hermenêutica filosófica, como contendo idealizações não clarificadas. Nenhuma das formulações iniciais deste cânone oferece uma regra metodológica. Existem três formulações chamadas "objectivas" e quatro chamadas "subjectivas" (mais uma vez, omitimos aqui os detalhes). Para além disso, existe a questão de separar "compreensão" de "aplicação" numa presente situação, um tema que é especialmente relevante para o Direito. Todavia, a hermenêutica metodológica requer que a compreensão seja uma tarefa separada e anterior. De acordo com Seebohm, a primeira formulação, que se aproxima mais de um princípio básico do método histórico-filológico - ou seja, de um princípio de hermenêutica metodológica, que vai além de regras ou procedimentos específicos para questões da "validade objectiva das interpretações orientadas por métodos (HMM 152) -, reza assim:

O texto não deve ser compreendido fora do contexto do intérprete: deve ser compreendido fora do seu próprio contexto e fora do contexto dos comentários contemporâneos. (HMM 167) 
Para Schütz, as coisas com sentido são "todas as coisas naturais, [...] todos os seres vivos (especialmente [...] os seres humanos) e [...] produtos com sentido de todos os tipos (ferramentas, símbolos, sistemas de linguagem, obras de arte, etc.)" (CP I 135, cf. CPI 10). Se bem que a ênfase de Schütz resida na acção, podemos concentrar-nos nos textos escritos para o propósito da nossa presente comparação. O sentido do texto é fundamentalmente uma questão do que Max Weber chamou de subjektiver Sinn, que Schütz tendeu cada vez mais a traduzir como "interpretação subjectiva" [subjective interpretation]. O comentário que se segue, no que diz respeito a este termo, aparece num ensaio tardio.

O sentido subjectivo [...] é o sentido que uma acção tem para o actor ou que uma relação ou situação têm para uma pessoa ou pessoas envolvidas na mesma; o sentido objectivo é o sentido que a mesma acção, relação ou situação tem para quaisquer outras pessoas, quer seja um parceiro ou observador na vida diária, um cientista social ou um filósofo. A terminologia é infeliz, porque o termo "sentido objectivo" é obviamente um nome errado, porquanto as chamadas interpretações "objectivas" são, por sua vez, relativas às atitudes particulares dos intérpretes e, por conseguinte, num certo sentido, "subjectivas". (CP II 275)

Para os textos da região dos contemporâneos, a investigação é relativa à interpretação subjectiva do próprio autor. Não só o intérprete deve evitar impingir a sua própria interpretação do texto e do seu contexto, mas pode também pedir ao autor esclarecimentos adicionais na escrita. Isto é uma extensão para o nível lexical de uma possibilidade na entrevista oral a um consociado.

Para a interpretação dos textos dos predecessores, o mesmo é dizer, para a história, esses novos textos, todavia, não podem mais ser obtidos (contudo, podem ser descobertos outros textos anteriormente desconhecidos). No entanto, para Schütz, é ainda verdade que aquilo que o historiador está a procurar, para desenvolver uma interpretação "objectiva", é a própria interpretação subjectiva dos predecessores, no seu contexto subjectivo da vida diária (PSW §41). O primeiro cânone da Hermenêutica pode ser considerado, por conseguinte, como uma especificação, no caso dos textos dos predecessores, do postulado da interpretação subjectiva, de Schütz.

Além disso, o postulado da adequação, de Schütz, requer que o modelo cultural-científico seja "razoável e compreensível para o próprio actor" (CP II 85). Contudo, na erudição histórica, podemos apenas recorrer àquilo que é expresso em outros lugares do texto, nas outras obras do autor ou no seu género. Por outras palavras, perguntamo-nos, caso o predecessor fosse vivo, se consideraria o contributo do historiador inteligível e razoável. Existem muito mais postulados descritos em Schütz, mas os dois mencionados mostram uma convergência prima facie com Seebohm. 
Seguindo August Boeckh e outros, a hermenêutica metodológica de Seebohm vai para além da mera hermenêutica "metódica" ao incluir, ultimamente, o problema da justificação objectiva. Pode parecer que Schütz é um verificacionista. ${ }^{9}$ A questão diz respeito ao que os investigadores fazem quando consideram o quanto os resultados obtidos previamente podem ser criticados, e Seebohm salienta explicitamente o falsificacionismo. "Os hermeneutas do século XIX, orientados metodologicamente, sabiam que os seus métodos são métodos para evitar o erro [...]. Os métodos não são garantias da verdade das interpretações. De facto, nunca houve e nunca haverá uma interpretação filológica absolutamente verdadeira. [...] Mesmo interpretações corroboradas são ainda um tema de verificações críticas. Elas são verdadeiras no sentido de 'ainda não falsificadas'” (HMM 240).

Como procede a crítica das interpretações? Como já foi indicado, uma interpretação de nível superior em conflito com uma interpretação de nível inferior deve ser rejeitada. Os árbitros últimos são as interpretações gramaticais e lexicográficas, que se baseiam numa comparação das formas das frases e dos usos das palavras nas frases. Para Schütz, e devido ao postulado da adequação, poderia parecer que as interpretações "objectivas", pelos cientistas da cultura, pelos filósofos bem como pelos metodologistas científicos, devem ser rejeitadas, se entrarem em conflito com as interpretações subjectivas dos actores na vida diária, e que as pretensões teorético-científicas gerais a respeito da investigação científico-social devem ser rejeitadas, se não forem consideradas "razoáveis e compreensíveis" pelos próprios cientistas.

\section{Convergência e continuação}

A complementaridade entre Schütz e Seebohm, esboçada acima, é bastante encorajante para a teoria das Ciências da Cultura. As Ciências Humanas, ou da cultura, são reconhecidas por ambos como incluindo as ciências históricas e as sociais ou "sistemáticas", que tematizam aspectos do mundo-da-vida sócio-cultural. E, apesar de Schütz e Seebohm enfatizarem questões diferentes, eles fazem contribuições convergentes para a teoria geral da compreensão. Contudo, como foram desenvolvidas estas contribuições?

Alfred Schütz bebeu em Weber, Thomas Seebohm, nos hermeneutas do século XIX, desde Schleiermacher a Dilthey, mas ambos afirmam apoiar-se, em última instância, na Fenomenologia Constitutiva da Atitude

9 "Eu estou de acordo com o Professor Nagel que todo o conhecimento empírico envolve a descoberta mediante processos de inferência controlada, e que isso deve ser exposto numa forma proposicional susceptível de ser verificada por alguém que esteja disposto a fazer esforço através da observação..." (CP I 51). 
Natural, de Husserl. Por conseguinte, mesmo que fosse o caso de nada ter sido acrescentado ou corrigido ao pensamento que ambos receberam (coisa que não está aqui a ser defendida!), a sua base explícita de recepção está para além de Dilthey ou Weber e não é filológica.

Seebohm não analisa, no seu livro, a focagem que é própria da Fenomenologia, apenas menciona de passagem as "descrições reflexivo-eidéticas, de Husserl" (HMM 200), mas Schütz oferece duas análises especialmente pertinentes. Em primeiro lugar, ele escreve que, "permanecendo ainda na atitude natural, e isto significa: sem pôr em prática a redução transcendental, eu posso sempre virar-me, num acto de reflexão, dos objectos dos meus actos e pensámentos para o meu agir e pensar. Fazendo isso, faço dos meus actos e pensamentos prévios os objectos de outro pensamento, o pensamento reflexivo, através do qual os apreendo. Então, o meu 'Eu', que tem sido escondido, até ao momento, pelos objectos dos meus actos e pensamentos, emerge" (I 169). E, em segundo lugar, "uma Psicologia, da qual se espera uma solução dos problemas das Ciências da Cultura, deve estar ciente do facto de que não é uma ciência que lide com factos empíricos. Tem de ser uma ciência das essências [...]. Consequentemente, tem de analisar as estruturas invariáveis, peculiares e essenciais da mente; mas isto será o mesmo que dizer que examina a sua estrutura $a$ priori $[\ldots] . . "$ (CP I 132; cf. I 113 ff.).

Estes dois pontos oferecem mais do que um mero relato de como as contribuições de Schütz e Seebohm, na teoria fenomenológica das ciências da cultura, conscientemente concorreram. Também indicam como tais contribuições podem ser confirmadas, corrigidas e alargadas, por exemplo, no que diz respeito a uma teoria fenomenológica da Arqueologia, uma área que ainda precisa de muito trabalho. Um volume considerável de mais investigação é necessário para se compreender como é que o mundo sócio-cultural é abordado nas várias ciências sociais e históricas, e as duas contribuições, tomadas em conjunto, proporcionam um melhor ponto de partida do que tomadas isoladamente.

Tradução de Joana Luís

Revisão de Pedro M. S. Alves 


\begin{abstract}
Alfred Schutz emphasizes the methods of interpretative social sciences. Thomas Seebohm emphasizes the interpretation of texts and traces essential to the historical sciences. There their accounts are, in the main, mutually complementary, and together they advance the constitutive phenomenological theory of the generically cultural sciences.
\end{abstract}

